\title{
Characteristics of Carbon Nanotubes/Graphene Coatings on Stainless Steel Meshes Used as Electrodes for Air-Cathode Microbial Fuel Cells
}

\author{
Wei-Hsuan Hsu, ${ }^{1}$ Hung-Yin Tsai, ${ }^{2}$ and Ying-Chen Huang ${ }^{2}$ \\ ${ }^{1}$ Department of Mechanical Engineering, National United University, Miaoli 36003, Taiwan \\ ${ }^{2}$ Department of Power Mechanical Engineering, National Tsing Hua University, Hsinchu 30013, Taiwan \\ Correspondence should be addressed to Hung-Yin Tsai; hytsai@pme.nthu.edu.tw
}

Received 3 October 2016; Revised 13 February 2017; Accepted 16 March 2017; Published 16 April 2017

Academic Editor: Genggeng Qi

Copyright (c) 2017 Wei-Hsuan Hsu et al. This is an open access article distributed under the Creative Commons Attribution License, which permits unrestricted use, distribution, and reproduction in any medium, provided the original work is properly cited.

\begin{abstract}
Microbial fuel cells (MFCs) generate low-pollution power by feeding organic matter to bacteria; MFC applications have become crucial for energy recovery and environmental protection. The electrode materials of any MFC affect its power generation capacity. In this research, nine single-chamber MFCs with various electrode configurations were investigated and compared with each other. A fabrication process for carbon-based electrode coatings was proposed, and Escherichia coli HB101 was used in the studied MFC system. The results show that applying a coat of either graphene or carbon nanotubes (CNTs) to a stainless steel mesh electrode can improve the power density and reduce the internal resistance of an MFC system. Using the proposed surface modification method, CNTs and graphene used for anodic and cathodic modification can increase power generation by approximately 3-7 and 1.5-4.5 times, respectively. Remarkably, compared to a standard MFC with an untreated anode, the internal resistances of MFCs with CNTs- and graphene-modified anodes were reduced to 18 and 30\% of standard internal resistance. Measurements of the nine systems we studied clearly presented the performance levels of CNTs and graphene applied as surface modification of stainless steel mesh electrodes.
\end{abstract}

\section{Introduction}

As technology advances, energy consumption and shortfalls of energy supply are inevitable. Moreover, the rise of environmental awareness has motivated the development of minimally polluting renewable energy sources, such as microbial fuel cells (MFCs). Thus, MFCs have been extensively studied in the last decade. MFCs utilize microorganisms as catalysts to decompose organic or inorganic matter and harvest electrical energy [1].

The major obstacles towards commercialization of MFC are its high cost of fabrication and low power output. The cost of MFC mainly depends on the design of reactors, membrane separator, and electrode catalysts [2-4]. A typical MFC system comprises two chambers (i.e., an anode and a cathode) separated by a proton exchange membrane (PEM). Chemical energy can be converted to electric energy through anodic oxidation and cathodic reduction. Microorganisms oxidize the organic compound and produce electrons and protons in the anode chamber. Electrons are transported to the cathode by an external circuit, whereas the protons are transferred internally to the cathode chamber through the PEM. Subsequently, the electrons and protons react with oxygen to form water. According to the energy conversion process, the electric current can be generated continuously between the anode and cathode [5-7]. To allow the easy construction, a single-chamber MFC system was proposed [8], in which the cathodic and anodic electrodes were placed in a reaction chamber and a proton exchange membrane (PEM) was fused to the cathodic surface. Later, the performance of air-cathode single-chamber MFCs was further investigated to reduce the cost of MFC, and the feasibility of MFC systems without PEM materials was demonstrated [9]. Because oxygen can pass through the cathode directly in air-cathode MFC designs, these designs reduce the cost of equipment required to regulate air exposure. Thus, a single-chamber MFC has some 
advantages over a traditional double-chamber MFC and has potential for development.

The power output of an MFC is affected by several factors, including the microbial inoculation, electrode materials, ionic concentration, catalyst, internal resistance, and electrode spacing [10-13]. The electrode materials play a critical role in electricity generation. An electrode with high electrical conductivity can effectively collect electrons and reduce ohmic loss. Therefore, metal electrodes are crucial for MFC systems. Conventionally, designers choose stainless steel and titanium for electrodes in MFC systems [14]. Stainless steel has the advantages of low cost and anticorrosive properties, and it has become one of the major research materials for electrodes in MFCs. However, in MFC systems, electrons are generated by metabolically and electrochemically active microorganisms at the interfaces between anodic surfaces and microbes $[15,16]$, and the generated electrons transfer to anode surfaces through direct contact, microbial pili, or soluble mediators $[17,18]$. Thus, an electrode with a large surface area and high specific surface area can demonstrate high microbe attachment and low internal resistance [19]. To improve the attachment of bacteria on the anode, an electrode with a high specific surface area is necessary. For this purpose, numerous studies have utilized threedimensional structures of stainless steel, such as stainless steel mesh (SSM) [20-25], stainless steel foam [26], stainless steel felt [27], and stainless steel fiber felt [28-31]. But the surface areas of this type of electrode are limited when compared with those of nanomaterial-based electrodes. Nanomaterials offer exceptionally large surface-area-to-volume ratios as well as unique electrochemical properties such as strong charge interactions with organic matter [32]. Therefore, most of the aforementioned studies have used nanomaterials for electrode modification treatment.

In recently years, carbon nanotubes (CNTs) and graphene have been intensively studied and explored in various applications for advanced technologies due to their fascinating properties, such as high electrical conductivity, surface area, and stability [33, 34]. Moreover, CNTs [21, 23, 32, 35-37] and graphene $[20,30,37]$ have been used as an electrode modified material in MFC systems. Research has confirmed that SSM electrodes modified with CNTs or graphene can improve the characteristics of MFCs. For anode modification, graphene can improve electrode surface area, adhesion of bacteria, and efficiency of electron transfer [20]. Some MFCs with CNTs-SSM cathodes have achieved levels of maximum power density and Coulombic efficiency higher than those of MFCs with bare SSM cathodes [21, 23]. However, the aforementioned studies have studied diverse modification processes and coating materials with different properties. To accelerate the development of MFCs, the performance effects of SSM electrodes coated with CNTs or graphene must be comprehensively compared using the same modification process and coating materials. Thus, in this study, a set of mediatorless single-chamber MFCs was designed to examine the performance effects of different SSM electrodes coated with CNTs or graphene. The power density and internal resistance values of the MFCs with CNT- or graphene-coated electrodes were evaluated as the performance indices.

\section{Materials and Methods}

2.1. Electrode Modification. The process of electrode modification was described as follows. For anodic modification, carbon ink was prepared by dispersing $20 \mathrm{mg}$ of multiwall CNTs (MW-CNTs; average diameter larger than $50 \mathrm{~nm}$, length between 10 and $20 \mu \mathrm{m}$, and specific surface area approximately $60 \mathrm{~m}^{2} / \mathrm{g}$ ) or multilayer graphene sheets (MG; specific surface area approximately $20 \mathrm{~m}^{2} / \mathrm{g}$, average sheet thickness smaller than $50 \mathrm{~nm}$, and lateral size approximately $20 \mu \mathrm{m})$ in $95 \%$ ethanol $(10 \mathrm{~mL})$. Ethanol with MW-CNTs or MG was ultrasonicated to obtain a homogeneous solution. A piece of SSM (average hole diameter $40 \mu \mathrm{m}$, thickness $100 \mu \mathrm{m}$, and diameter $50 \mu \mathrm{m}$ ) was then dipped into the carbon ink for 1 hour, removed, and finally baked at $150^{\circ} \mathrm{C}$ for 1 hour to obtain an SSM anode coated with MW-CNTs or MG.

For cathodic modification, polytetrafluoroethylene (PTFE) solution, with or without carbon-based materials, was used for waterproofing. The treated PTFE solution was prepared by dispersing $20 \mathrm{mg}$ of $\mathrm{MW}-\mathrm{CNTs}$ or $\mathrm{MG}$ in $19.98 \mathrm{~g}$ of PTFE solution (preparation $60 \mathrm{wt} \%$ dispersion in $\mathrm{H}_{2} \mathrm{O}$ ). The dispersion was performed using ultrasonic vibration to obtain a homogeneous solution. A piece of SSM was soaked in the pure or treated PTFE solution for 1 hour, removed, and then baked at $235^{\circ} \mathrm{C}$ for 1 hour. The soaking-baking process was repeated four times to obtain a cathode with excellent waterproofing. In some study cases, platinum $\left(0.5 \mathrm{mg} / \mathrm{cm}^{-2}\right.$, $20 \mathrm{wt} \% \mathrm{Pt} / \mathrm{C}$ ) was used to catalyze the oxygen reaction. For those case studies, the inner side of the cathode, which served as the contact surface with the reaction environment, was covered with a Pt catalyst after waterproofing and baked for 30 minutes at $350^{\circ} \mathrm{C}$.

2.2. Microorganism Culture. A single bacterium, Escherichia coli HB101, was used to convert energy; this reduced the experimental variability and facilitated precise estimation of the effects of electrode modifications on MFC performance levels. The culture process resembled the methods of a previous study [37] and is briefly described as follows: E. coli $\mathrm{HB101}$ was grown anaerobically in an atmosphere of $\mathrm{N}_{2}$ gas for 40 hours until it reached its stationary phase in lysogeny broth medium at $37^{\circ} \mathrm{C}$. After culturing, the microbe was obtained by $5000 \mathrm{rpm}$ centrifugation and then dissolved in M9 medium.

2.3. MFC Structure. The structure of the air-cathode MFC used in this study, which resembles previously reported MFCs [37], is shown in Figure 1. In this air-cathode MFC, the material of the cylindrical chamber was polymethylmethacrylate (PMMA) and its diameter, length, wall thickness, and reactor volume were approximately $50 \mathrm{~mm}, 60 \mathrm{~mm}$, $5 \mathrm{~mm}$, and $75 \mathrm{~mL}$, respectively. Anodic and cathodic electrodes were placed at the ends of the cylindrical chamber; the cathodic electrode was on the side with air, and the anodic electrode was on the opposite side. The surface areas of the cathode and anode were approximately $1257 \mathrm{~mm}^{2}$. Additionally, copper wires and resistors were used to connect the circuit. 
TABLE 1: Electrode conditions of the MFC systems.

\begin{tabular}{lcc}
\hline Experimental cases & Anode & Electrode \\
\hline MFC-NE & Normal & PTFE \\
MFC-GE & MG & PTFE \\
MFC-CE & MW-CNTs & PTFE \\
MFC-NPE & Normal & Pt + PTFE \\
MFC-GPE & MG & Pt + PTFE \\
MFC-CPE & MW-CNTs & Pt + PTFE \\
MFC-NGE & Normal & MG + PTFE \\
MFC-NCE & Normal & MW-CNTs + PTFE \\
MFC-NPGE & Normal & Pt + MG + PTFE \\
\hline
\end{tabular}

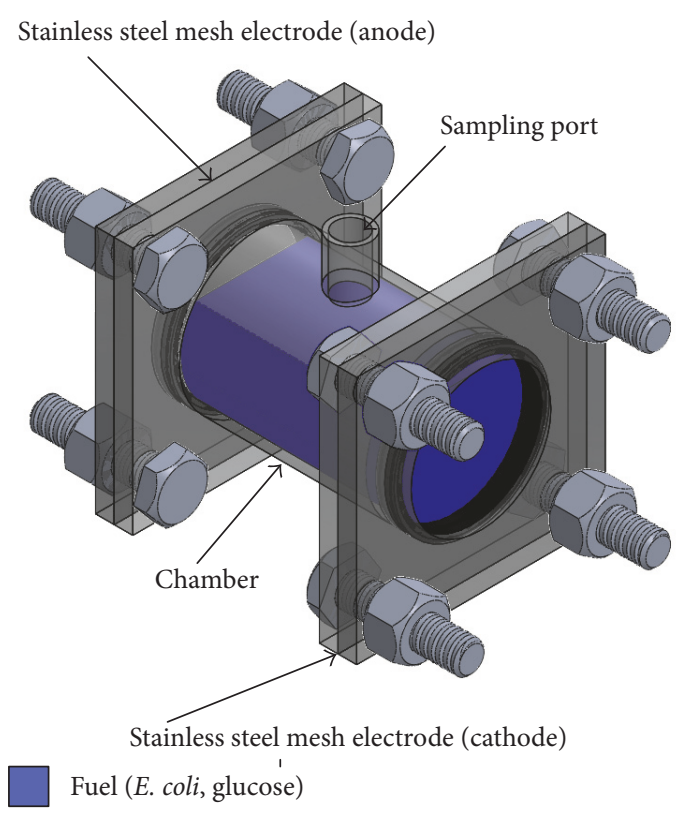

FIGURE 1: Schematic of the air-cathode MFC used in this study. Different types of SSMs can be used as electrodes and connected to external resistance loads with copper wires.

\subsection{Experimental Planning and Measurement. Nine types} of single-chamber MFCs were constructed, as shown in Figure 2, to compare the effects of electrodes coated with MW-CNTs and MG on MFC system performance. These nine types of MFCs were named as listed in Table 1. The anodic condition was represented in the first letter, and the cathodic condition was represented in the second, third, and fourth letters. Among them, the letters "N," "G," and "C" represented the normal, MG-modified, and MW-CNTsmodified SSMs, respectively. Additionally, the letter "E" represented the cathode covered with pure PTFE, and "P" represented the cathode with Pt catalyst.

Stable values of power density and internal resistance were selected to compare the effects of MW-CNTs and MG on MFC system performance. The methods of measurement and calculation are described as follows. A digital electronic multimeter was employed to record the cell voltage. Before determination, a resistance of $1 \mathrm{k} \Omega$ was used as the external load. When the voltage output was stable, the cell voltage was recorded to evaluate the power generation. External resistance was varied from 1 to $20 \mathrm{k} \Omega$ to obtain the cell voltage of the MFC under testing, and then the performance of the MFCs was evaluated through the polarization and power density curves. Power density $P\left(\mathrm{Wm}^{-2}\right)$ was calculated according to the equation $P=I V / A$, in which $I(\mathrm{~A}), V(\mathrm{~V})$, and $A\left(\mathrm{~m}^{2}\right)$ were the current, voltage, and electrode area, respectively. The slope of the polarization curve was used to determine the internal resistance of the MFC under test. The internal resistance $\left(R_{\mathrm{in}}, \Omega\right)$ was calculated from the polarization slope according to the equation $R_{\text {in }}=\Delta V / \Delta I$, in which $\Delta V(\mathrm{mV})$ and $\Delta I(\mathrm{~mA})$ were the voltage difference and current difference between two points of the polarization curve, respectively. The measurements were performed at a controlled temperature of $30^{\circ} \mathrm{C}$.

\section{Results and Discussion}

3.1. Morphology of Electrode Surfaces. The results of the anodic modification were photographed through a scanning electron microscope (SEM) and are shown in Figures 3 and 4, which present the surface morphologies of SSM anodes coated with MW-CNTs and MG, respectively. The coating process resulted in thick coatings of MW-CNTs or MG on SSM surfaces, and the surface morphologies of the coatings were very similar at all locations. The MW-CNTs and MG were uniformly distributed over the SSM surfaces. Each MW-CNTs coating appeared to form an interconnected network, whereas each MG coating appeared to form a stacked sheet structure. According to the overall distributions of the MW-CNTs and MG on the SSMs, we can confirm that homogeneous and stable MW-CNTs- and MG-modified SSM electrodes can be fabricated by using this simple coating process.

The results of cathode modification are shown in Figure 5, in which panels (a) and (b) show the coating results when the PTFE solutions were mixed with the MG and MW-CNTs, respectively. Both types of treated PTFE (pure PTFE mixed with MG or MW-CNTs) completely coated the SSM surfaces. Moreover, the surface roughness of the PTFE mixed with the MW-CNTs was notably more pronounced than that of 

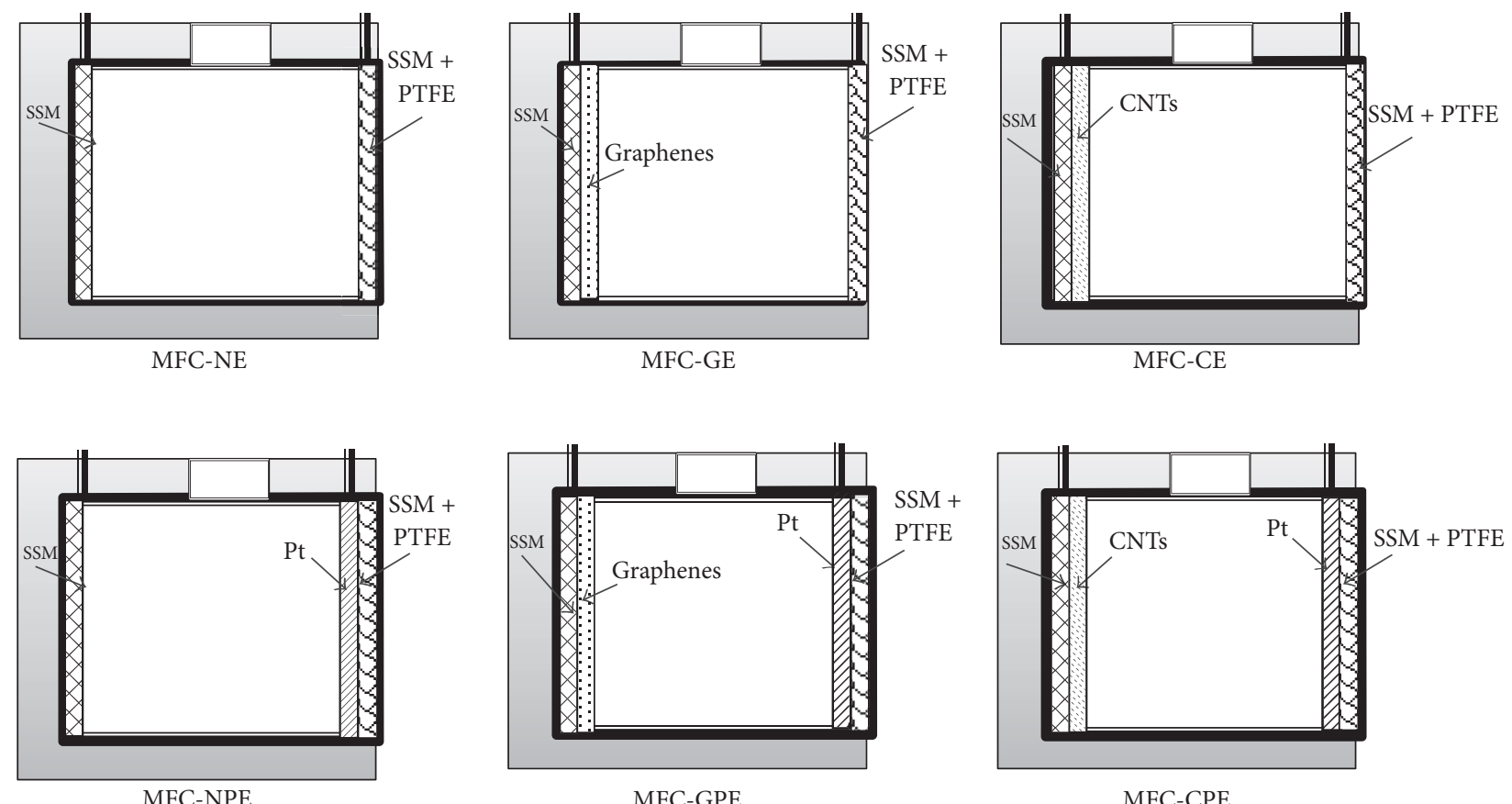

MFC-GPE

MFC-CPE
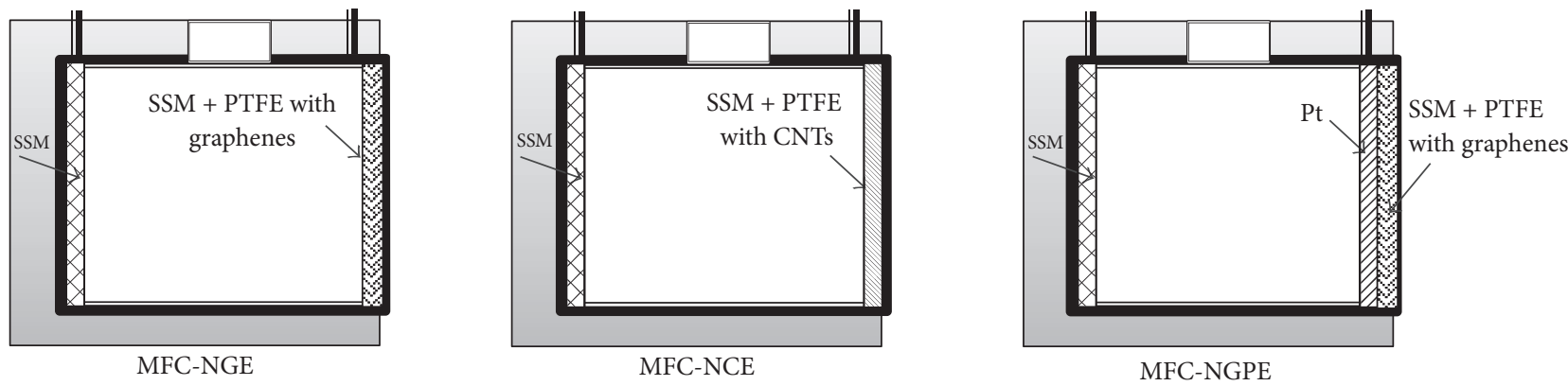

SSM
SSM + PTFE
SSM + PTFE with graphenes
SSM + PTFE with CNTs

FIGURE 2: Schematic of the electrode conditions in the studied case.

the PTFE mixed with the MG, as can be seen by comparing Figure 5(a) with Figure 5(b).

3.2. Performance of MFCs. To realize the diverse effects of differently coated anodic surfaces on MFC performance, three types of anodes with PTFE-coated cathodes (MFC-NE, MFC$\mathrm{GN}$, and MFC-CN) were selected for analysis. The results are shown in Figure 6, in which the solid data points represent the power densities and the hollow data points represent the cell voltages. In the case of MFC-NE, the maximum power density was $69.1 \mu \mathrm{W} / \mathrm{m}^{2}$. With an anode that was coated with MG (the case of MFC-GE), the maximum power density was $231 \mu \mathrm{W} / \mathrm{m}^{2}$. In the case of MFC-CE, MW-CNTs were the coating material, and the power density was $490 \mu \mathrm{W} / \mathrm{m}^{2}$. The power density of MFC-GE was approximately 3.3 times that of MFC-NE, whereas the power density of MFC-CN was approximately seven times that of MFC-NE. Coating MG or MW-CNTs onto anodes can improve the efficiency of MFCs; this may be attributable to improved electron transfer routes resulting from the increased surface area of the anodes $[19,20,32]$.

In the cases of MFC-NPE, MFC-GPE, and MFC-CPE, all of the cathodes were covered with pure PTFE and then coated with $\mathrm{Pt}$, whereas each of the three anodes received a different treatment (MG, MW-CNTs, or nothing). The results of these three cases are shown in Figure 7. The maximum power densities of MFC-NPE, MFC-GPE, and MFC-CPE 

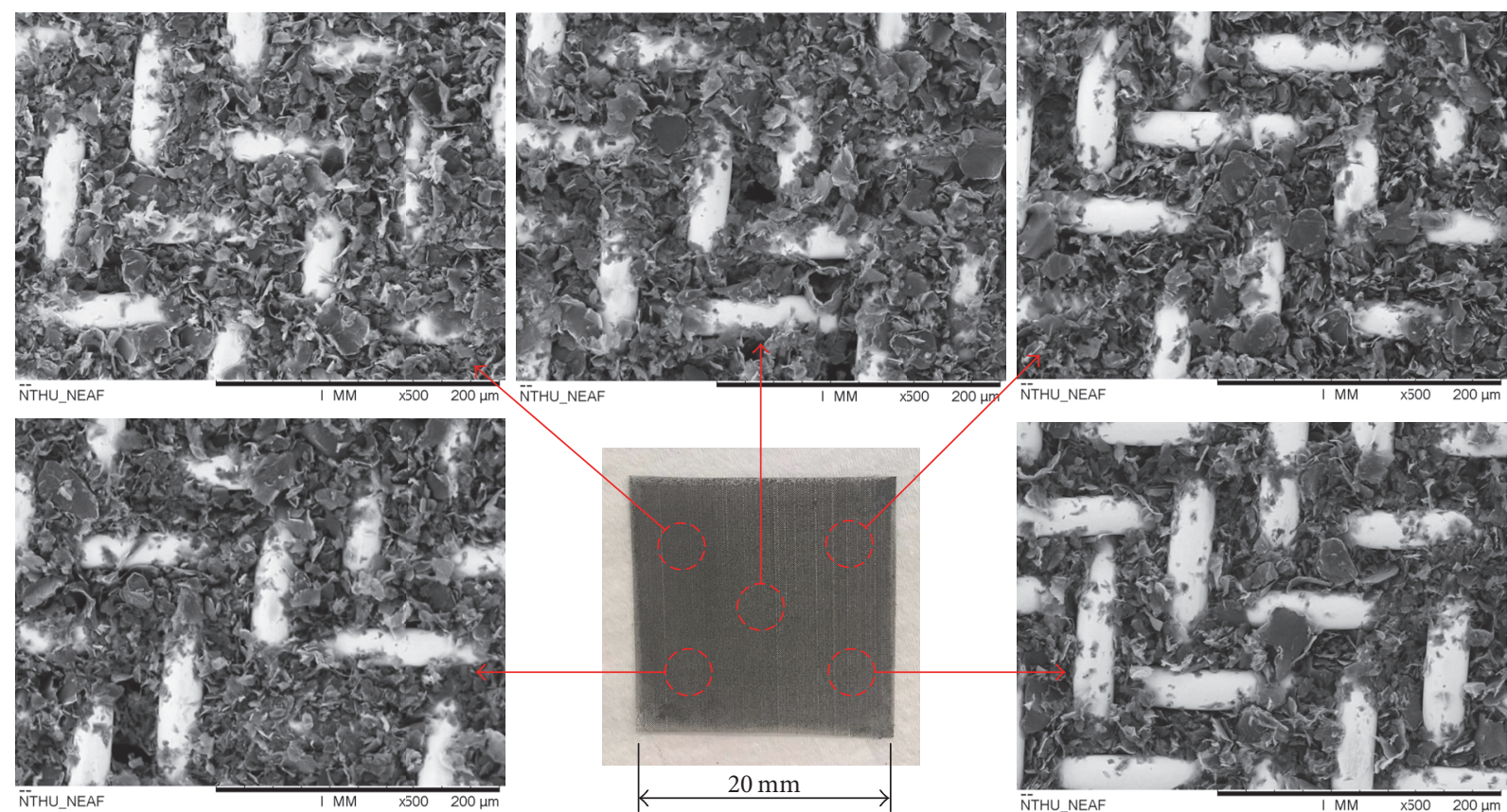

FIGURE 3: SEM images of MG on an SSM anode.
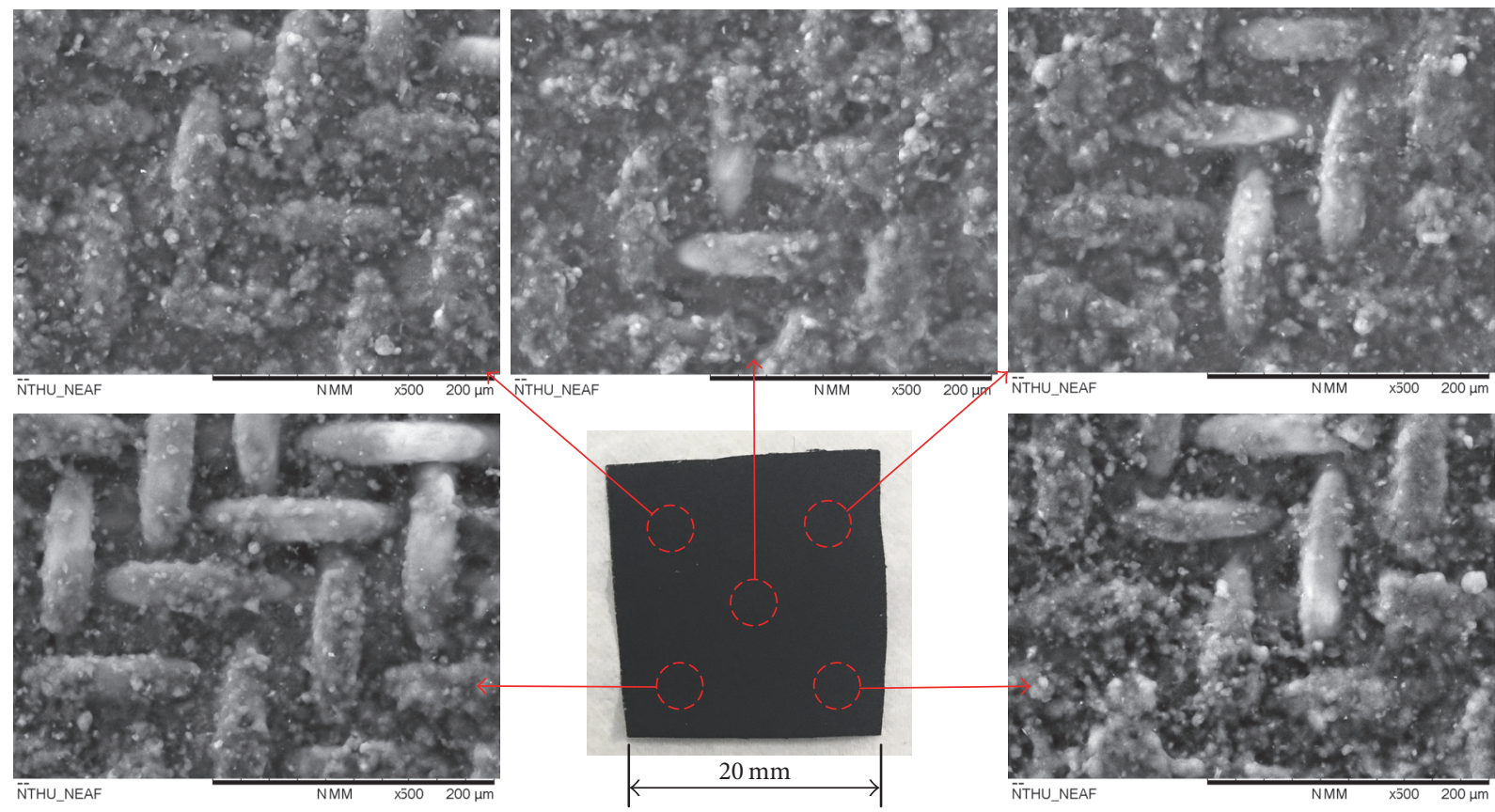

FIGURE 4: SEM images of MW-CNTs on an SSM anode.

were $92.1 \mu \mathrm{W} / \mathrm{m}^{2}, 2.9 \mathrm{~mW} / \mathrm{m}^{2}$, and $2.85 \mathrm{~mW} / \mathrm{m}^{2}$, respectively. The maximum power densities of MFC-GPE and MFC-CPE were over 30 times larger than those of MFC-NPE, indicating that adding MG or MW-CNTs to an anode can substantially improve power generation. Notably, the trends in cell voltage and power density illustrated in Figure 7 are similar to those in Figure 6. Moreover, comparing Figure 5 with Figure 6, the cathode with Pt displayed a higher cell voltage and current density than did the cathodes without Pt. In other words, Pt further improved the power generation, which may be attributable to Pt catalyzing the oxygen reaction.

The effects of modified cathodes on MFC performance were evaluated, as shown in Figures 8 and 9. In Figure 8, the maximum power density of MFC-NPE is $92.95 \mu \mathrm{Wm}^{-2}$ and that of MFC-NE is $69.1 \mu \mathrm{Wm}^{-2}$. These two power densities differed by a factor of approximately 1.35 . Thus, the cathode 


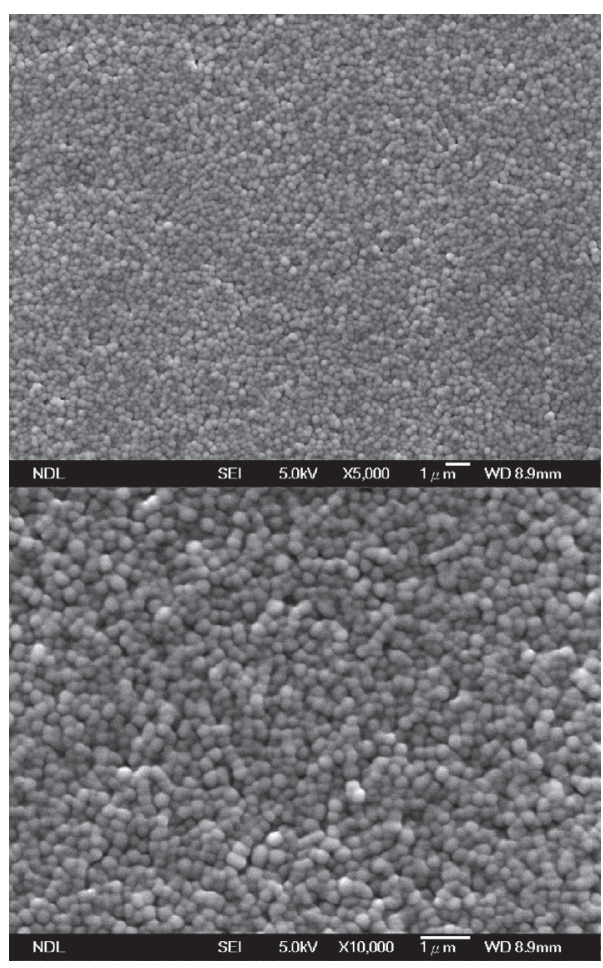

(a)

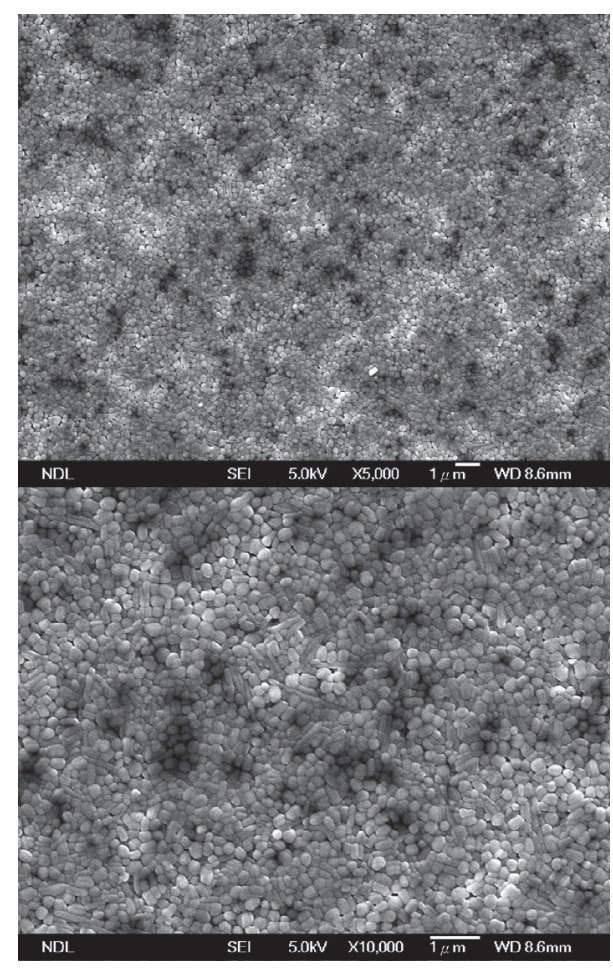

(b)

FIGURE 5: SEM images of cathodes covered with treated PTFE. (a) PTFE mixed with MG. (b) PTFE mixed with MW-CNTs.

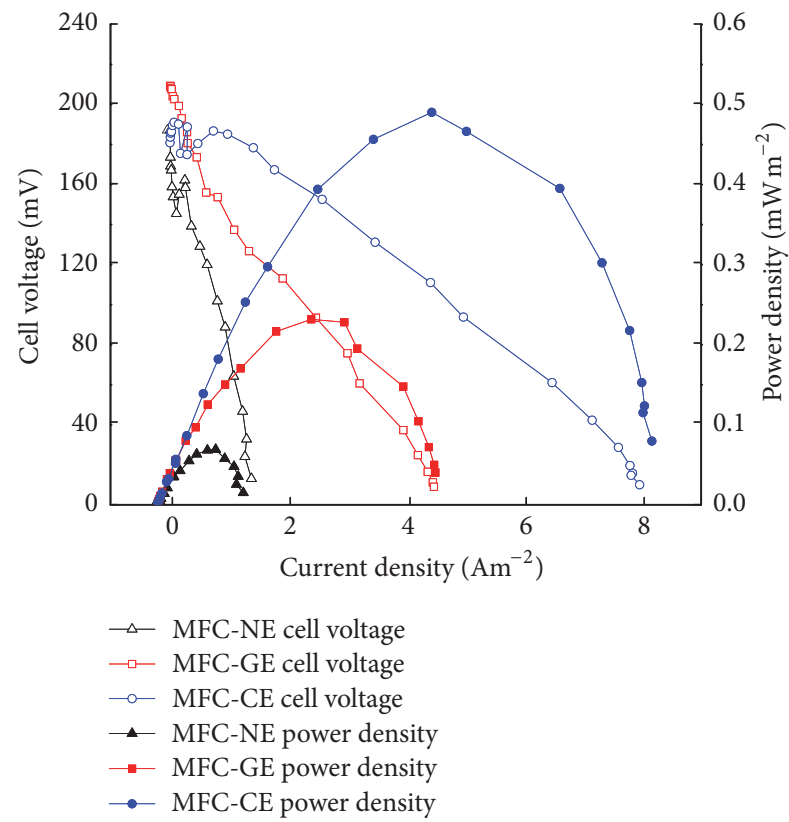

FIgURE 6: Performance of systems with PTFE-coated cathodes and with anodes coated with different materials.

coated with Pt catalyzed the oxygen reaction and enhanced MFC performance. Additionally, the polarization curves of MFC-NGE and NCE can be used to understand the effects of PTFE mixed with MG and MW-CNTs, respectively, on

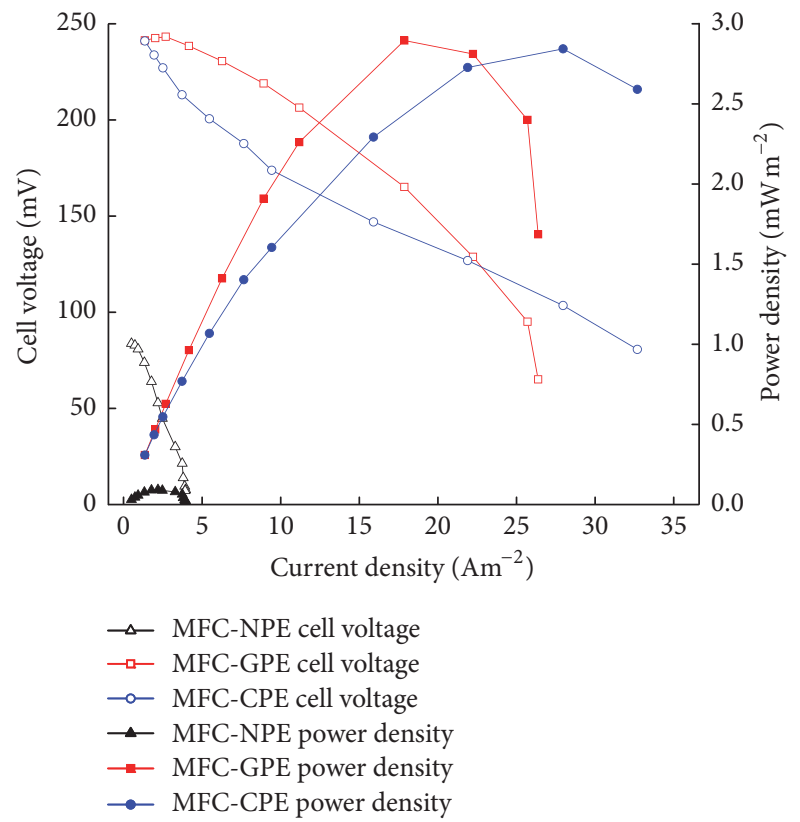

FIGURE 7: Performance of systems with anodes coated with MG, MW-CNTs, or nothing, and with Pt/PTFE-coated cathodes.

MFC performance. The maximum power densities of MFCNGE and NCE were 116.5 and $314 \mu \mathrm{W} / \mathrm{m}^{2}$, respectively. The power densities obtained by MFC-NGE and MFC-NCE were 

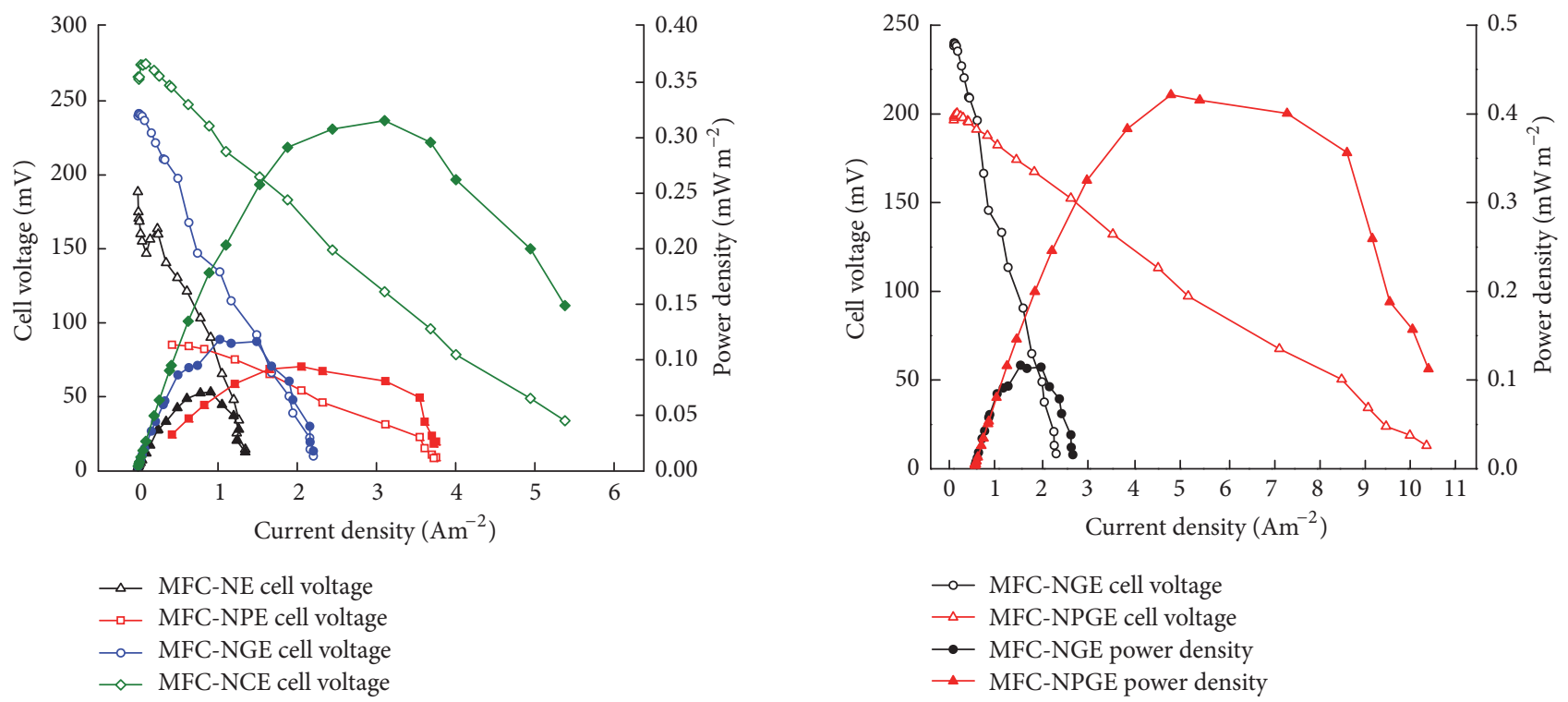

FIGURE 9: Performance of systems with cathodes coated with graphene-treated PTFE and platinum.

FIGURE 8: Performance of systems with cathodes coated with different materials and with uncoated SSM anodes.

approximately 1.7 and 4.5 times greater than those of MFCNE. These results showed that mixing PTFE with MW-CNTs or MG to serve as a waterproof layer of the cathode can enhance the efficiency of power generation.

To compare the maximum power densities among various MFC systems as shown in Figure 8, the MG-modified cathode exhibited a similar power generation to the cathode with Pt catalyst, while the MW-CNTs-modified cathode generated more power than the MG-modified cathode (which was potentially due to the rough surface of the cathode that was observed through SEM analysis). Moreover, MG and MW-CNTs have the potential to replace Pt as a cathode catalyst in air-cathode MFC systems. Such a replacement would notably reduce the cost of materials for cathode catalysts.

Figure 8 also reveals that power generation can be improved through various means, including coating cathodes with Pt, PTFE mixed with MG, or PTFE mixed with MW-CNTs. Therefore, the power generation effects of the simultaneous application of these cathode treatments were studied, and the results are presented in Figure 9. Notably, when the cathode was coated with MG-treated PTFE and platinum (the case of MFC-NPGE), the maximum power density was $421.5 \mu \mathrm{Wm}^{-2}$, which was approximately 3.6 times that of MFC-NGE. This confirms that power generation can be further increased when a platinum catalyst and treated PTFE are used simultaneously.

The objective of this study was to realize the modification effects of SSM electrodes by using carbon-based materials (MW-CNTs and MG). Therefore, experiments were conducted using a single species of microorganism. No electron transfer mediators were used because mediators might have

distorted the accurate assessment of the modification effects of electrodes; this is also why the MFC power output levels in this study were lower than those reported in most related research. Besides, among all the experimental trials, the MWCNTs-modified electrodes showed higher power generation than the MG-modified electrodes, regardless of whether the MW-CNTs were on the anode or on the cathode. A possible explanation is the differences in the surface area of MW-CNTs- and MG-coated SSMs. MW-CNTs and MG are adsorbed on SSM via carbon-metal bonding [38] or van der Waals interaction [22], and a large specific surface area can offer more adsorption sites [39]. In the studied cases, the specific surface areas of MW-CNTs and MG are approximately 60 and $20 \mathrm{~m}^{2} / \mathrm{g}$, respectively. Thus, the adsorptive properties of MW-CNTs with SSM should be better than those of the MG. This claim can be further supported by SEM microphotographs, as shown in Figures 3 and 4. There is strong evidence that the number of MW-CNTs loading in SSM is larger than that of MG. MW-CNTs completely coated the SSM surfaces and formed a three-dimensional network structure. By contrast, part of the SSM surface was observable in the SSMs coated with MG. Therefore, the surface area of the stacked MG may be lower than that of the MW-CNTs.

According to the measurement data, the internal resistance was evaluated using the polarization slop method; Table 2 shows the results. Regarding anodic modification, the internal resistance was reduced from $101 \mathrm{k} \Omega$ for both of the normal electrodes (in the case of MFC-NE) to $30 \mathrm{k} \Omega$ (in the case of MFC-GE) and to $19 \mathrm{k} \Omega$ (in the case of MFC$\mathrm{CE}$ ) when the anodes were modified with MG and MWCNTs, respectively. Furthermore, the internal resistance was substantially reduced from $20 \mathrm{k} \Omega$ for a normal electrode with Pt catalyst (in the case of MFC-NPE) to $7 \mathrm{k} \Omega$ (in the case of MFC-GPE) and to $4 \mathrm{k} \Omega$ (in the case of MFC-CPE) when the anodes were coated with MG and MW-CNTs, respectively. 
TABLE 2: Internal resistances of the MFC system for different electrode conditions.

\begin{tabular}{lc}
\hline Experimental cases & $R_{\text {in }}(\mathrm{k} \Omega)$ \\
\hline MFC-NE & 101 \\
MFC-GE & 30 \\
MFC-CE & 19 \\
MFC-NPE & 20 \\
MFC-GPE & 7 \\
MFC-CPE & 4 \\
MFC-NGE & 83 \\
MFC-NCE & 36 \\
MFC-NPGE & 14 \\
\hline
\end{tabular}

Regarding cathodic modification, the internal resistance was reduced from $101 \mathrm{k} \Omega$ (in the case of MFC-NE) to $83 \mathrm{k} \Omega$ for the case of the MG-modified cathode (in the case of MFC-NGE) and markedly decreased to $36 \mathrm{k} \Omega$ for the case of the MW-CNTs-modified cathode (the case of MFC-NCP). However, when the cathode was coated with pure PTFE and Pt (in the case of MFC-NPE), the internal resistance was $20 \mathrm{k} \Omega$. Thus, a cathode coated with Pt has a more favorable internal resistance than does a device coated with PTFE mixed with MW-CNTs or MG. This may be explained by the amount of contact area between the materials used for modification and the reaction liquid. Additionally, internal resistance can be further improved by using Pt and treated PTFE. The internal resistance was reduced from $20 \mathrm{k} \Omega$ for a normal electrode with Pt catalyst (in the case of MFC-NPE) to $14 \mathrm{k} \Omega$ when the PTFE waterproof layer was mixed with MG (in the case of MFC-NPGE).

Comparing the performance levels of modified anodes with those of cathodes, it was noted that the anodic modification showed more obvious effects on the performance than did the cathodic modification. Moreover, the MFC systems with MW-CNTs-modified SSM electrodes showed lower internal resistance levels than those with MG-modified electrodes for the same electrode conditions. In summary, MW-CNTs- or MG-modified electrodes have lower internal resistance levels. The excellent electrical conductivity values and high surface areas of MW-CNTs and MG improve the efficiency of electron transmission.

\section{Conclusions}

Air-cathode MFCs were constructed using different types of composite electrodes, with or without MW-CNTs- or MGmodified SSMs. The experiments confirmed that the addition of MW-CNTs and MG enhanced the power density and reduced the internal resistance. Using MW-CNTs- or MGmodified anodes increased the maximum power density by approximately 7.1 and 3.1 times, respectively, compared with that of an untreated anode. Cathodes coated with PTFE solutions mixed with MW-CNTs and MG have maximum power densities, approximately 4.5 and 1.7 times, respectively, those of a cathode coated with pure PTFE solution. Additionally, internal resistances were substantially reduced from $101 \mathrm{k} \Omega$ for the normal case (MFC-NE) to $19 \mathrm{k} \Omega$ and $30 \mathrm{k} \Omega$ for the cases of anodic electrode modified by MW-CNTs (MFC-CE) and MG (MFC-GE), respectively. The electrodes modified with MW-CNTs showed superior power density and lower internal resistance than did those modified with MG. The surface area of the stacked MG may be lower than that of the MW-CNTs. The MW-CNTs coatings appeared to form interconnected networks rather than loosely overlaid MG, leading to the superior conductivity levels of MW-CNTscoated SSMs.

\section{Conflicts of Interest}

The authors declare no conflicts of interest.

\section{Acknowledgments}

The authors are grateful to Professor Hwan-You Chang (Department of Medical Science, National Tsing Hua University) for discussion and support regarding microbes. In addition, the authors acknowledge National Nano Device Laboratories for helping SEM imaging.

\section{References}

[1] D. R. Lovley, "Bug juice: harvesting electricity with microorganisms," Nature Reviews Microbiology, vol. 4, no. 7, pp. 497-508, 2006.

[2] J. Liu, Y. Feng, X. Wang et al., "The use of double-sided cloth without diffusion layers as air-cathode in microbial fuel cells," Journal of Power Sources, vol. 196, no. 20, pp. 8409-8412, 2011.

[3] M. T. Noori, C. Mukherjee, and M. Ghangrekar, "Enhancing performance of microbial fuel cell by using graphene supported $\mathrm{V}_{2} \mathrm{O}_{5}$-nanorod catalytic cathode," Electrochimica Acta, vol. 228, pp. 513-521, 2017.

[4] M. T. Noori, M. M. Ghangrekar, and C. K. Mukherjee, " $\mathrm{V}_{2} \mathrm{O}_{5}$ microflower decorated cathode for enhancing power generation in air-cathode microbial fuel cell treating fish market wastewater," International Journal of Hydrogen Energy, vol. 41, no. 5, pp. 3638-3645, 2016.

[5] B. E. Logan, B. Hamelers, R. Rozendal et al., "Microbial fuel cells: methodology and technology," Environmental Science and Technology, vol. 40, no. 17, pp. 5181-5192, 2006.

[6] D. R. Bond and D. R. Lovley, "Electricity production by Geobacter sulfurreducens attached to electrodes," Applied and Environmental Microbiology, vol. 69, no. 3, pp. 1548-1555, 2003.

[7] H. P. Bennetto, J. L. Stirling, K. Tanaka, and C. A. Vega, "Anodic reactions in microbial fuel cells," Biotechnology and Bioengineering, vol. 25, no. 2, pp. 559-568, 1983.

[8] H. Liu, R. Ramnarayanan, and B. E. Logan, "Production of electricity during wastewater treatment using a single chamber microbial fuel cell," Environmental Science and Technology, vol. 38, no. 7, pp. 2281-2285, 2004.

[9] H. Liu and B. E. Logan, "Electricity generation using an aircathode single chamber microbial fuel cell in the presence and absence of a proton exchange membrane," Environmental Science and Technology, vol. 38, no. 14, pp. 4040-4046, 2004.

[10] B. Cercado-Quezada, M.-L. Delia, and A. Bergel, "Treatment of dairy wastes with a microbial anode formed from garden 
compost," Journal of Applied Electrochemistry, vol. 40, no. 2, pp. 225-232, 2010.

[11] J. Menicucci, H. Beyenal, E. Marsili, R. A. Veluchamy, G. Demir, and Z. Lewandowski, "Procedure for determining maximum sustainable power generated by microbial fuel cells," Environmental Science and Technology, vol. 40, no. 3, pp. 1062-1068, 2006.

[12] B. E. Logan, C. Murano, K. Scott, N. D. Gray, and I. M. Head, "Electricity generation from cysteine in a microbial fuel cell," Water Research, vol. 39, no. 5, pp. 942-952, 2005.

[13] S. Cheng, H. Liu, and B. E. Logan, "Increased power generation in a continuous flow MFC with advective flow through the porous anode and reduced electrode spacing," Environmental Science and Technology, vol. 40, no. 7, pp. 2426-2432, 2006.

[14] J. Wei, P. Liang, and X. Huang, "Recent progress in electrodes for microbial fuel cells," Bioresource Technology, vol. 102, no. 20, pp. 9335-9344, 2011.

[15] W. Zhi, Z. Ge, Z. He, and H. Zhang, "Methods for understanding microbial community structures and functions in microbial fuel cells: a review," Bioresource Technology, vol. 171, pp. 461-468, 2014.

[16] N. S. Malvankar and D. R. Lovley, "Microbial nanowires: a new paradigm for biological electron transfer and bioelectronics," ChemSusChem, vol. 5, no. 6, pp. 1039-1046, 2012.

[17] K. Watanabe, M. Manefield, M. Lee, and A. Kouzuma, "Electron shuttles in biotechnology," Current Opinion in Biotechnology, vol. 20, no. 6, pp. 633-641, 2009.

[18] C. I. Torres, A. K. Marcus, H.-S. Lee, P. Parameswaran, R. Krajmalnik-Brown, and B. E. Rittmann, "A kinetic perspective on extracellular electron transfer by anode-respiring bacteria," FEMS Microbiology Reviews, vol. 34, no. 1, pp. 3-17, 2010.

[19] H. Ren, S. Pyo, J.-I. Lee et al., "A high power density miniaturized microbial fuel cell having carbon nanotube anodes," Journal of Power Sources, vol. 273, pp. 823-830, 2015.

[20] Y. Zhang, G. Mo, X. Li et al., "A graphene modified anode to improve the performance of microbial fuel cells," Journal of Power Sources, vol. 196, no. 13, pp. 5402-5407, 2011.

[21] Y. Chen, Z. Lv, J. Xu et al., "Stainless steel mesh coated with $\mathrm{MnO} 2 /$ carbon nanotube and polymethylphenyl siloxane as low-cost and high-performance microbial fuel cell cathode materials," Journal of Power Sources, vol. 201, pp. 136-141, 2012.

[22] S. Zheng, F. Yang, S. Chen et al., "Binder-free carbon black/ stainless steel mesh composite electrode for high-performance anode in microbial fuel cells," Journal of Power Sources, vol. 284, pp. 252-257, 2015.

[23] Y. Zhang, J. Sun, Y. Hu, S. Li, and Q. Xu, "Carbon nanotubecoated stainless steel mesh for enhanced oxygen reduction in biocathode microbial fuel cells," Journal of Power Sources, vol. 239, pp. 169-174, 2013.

[24] X. Li, X. Wang, Y. Zhang, N. Ding, and Q. Zhou, “Opening size optimization of metal matrix in rolling-pressed activated carbon air-cathode for microbial fuel cells," Applied Energy, vol. 123, pp. 13-18, 2014.

[25] M. L. Ullery and B. E. Logan, "Comparison of complex effluent treatability in different bench scale microbial electrolysis cells," Bioresource Technology, vol. 170, pp. 530-573, 2014.

[26] S. F. Ketep, A. Bergel, A. Calmet, and B. Erable, "Stainless steel foam increases the current produced by microbial bioanodes in bioelectrochemical systems," Energy and Environmental Science, vol. 7, no. 5, pp. 1633-1637, 2014.
[27] Z. Qiu, L. Wei, G. Wang, M. Su, and J. Shen, "Stainless steel felt as diffusion backing for high-performance microbial fuel cell cathodes," RSC Advances, vol. 5, no. 57, pp. 46210-46217, 2015.

[28] J. Hou, Z. Liu, S. Yang, and Y. Zhou, "Three-dimensional macroporous anodes based on stainless steel fiber felt for highperformance microbial fuel cells," Journal of Power Sources, vol. 258, pp. 204-209, 2014.

[29] M. Su, L. Wei, Z. Qiu, G. Wang, and J. Shen, "Hydrogen production in single chamber microbial electrolysis cells with stainless steel fiber felt cathodes," Journal of Power Sources, vol. 301, pp. 29-34, 2016.

[30] J. Hou, Z. Liu, Y. Li, S. Yang, and Y. Zhou, "A comparative study of graphene-coated stainless steel fiber felt and carbon cloth as anodes in MFCs," Bioprocess and Biosystems Engineering, vol. 38, no. 5, pp. 881-888, 2015.

[31] J. Hou, Z. Liu, and Y. Li, "Polyaniline modified stainless steel fiber felt for high-performance microbial fuel cell anodes," Journal of Clean Energy Technologies, vol. 3, no. 3, pp. 165-169, 2015.

[32] C. Erbay, X. Pu, W. Choi et al., "Control of geometrical properties of carbon nanotube electrodes towards high-performance microbial fuel cells," Journal of Power Sources, vol. 280, pp. 347354, 2015.

[33] R. H. Baughman, A. A. Zakhidov, and W. A. De Heer, "Carbon nanotubes-the route toward applications," Science, vol. 297, no. 5582, pp. 787-792, 2002.

[34] C. Lee, X. Wei, J. W. Kysar, and J. Hone, "Measurement of the elastic properties and intrinsic strength of monolayer graphene," Science, vol. 321, no. 5887, pp. 385-388, 2008.

[35] C. Wang, Y. Chen, Z. Qi, and Y. Yang, "Carbon nanotube planted on ni-based alloy in microbial fuel cell," Journal of Nanomaterials, vol. 2013, Article ID 435960, 5 pages, 2013.

[36] H.-Y. Tsai, C.-C. Wu, C.-Y. Lee, and E. P. Shih, "Microbial fuel cell performance of multiwall carbon nanotubes on carbon cloth as electrodes," Journal of Power Sources, vol. 194, no. 1, pp. 199-205, 2009.

[37] H.-Y. Tsai, W.-H. Hsu, and Y.-C. Huang, "Characterization of carbon nanotube/graphene on carbon cloth as an electrode for air-cathode microbial fuel cells," Journal of Nanomaterials, vol. 2015, Article ID 686891, 7 pages, 2015.

[38] S. Craig, G. L. Harding, and R. Payling, "Auger lineshape analysis of carbon bonding in sputtered metal-carbon thin films," Surface Science, vol. 124, no. 2-3, pp. 591-601, 1983.

[39] B. Dong, X. Guo, B. Zhang et al., "Heterogeneous ru-based catalysts for one-pot synthesis of primary amines from aldehydes and ammonia," Catalysts, vol. 5, no. 4, pp. 2258-2270, 2015. 

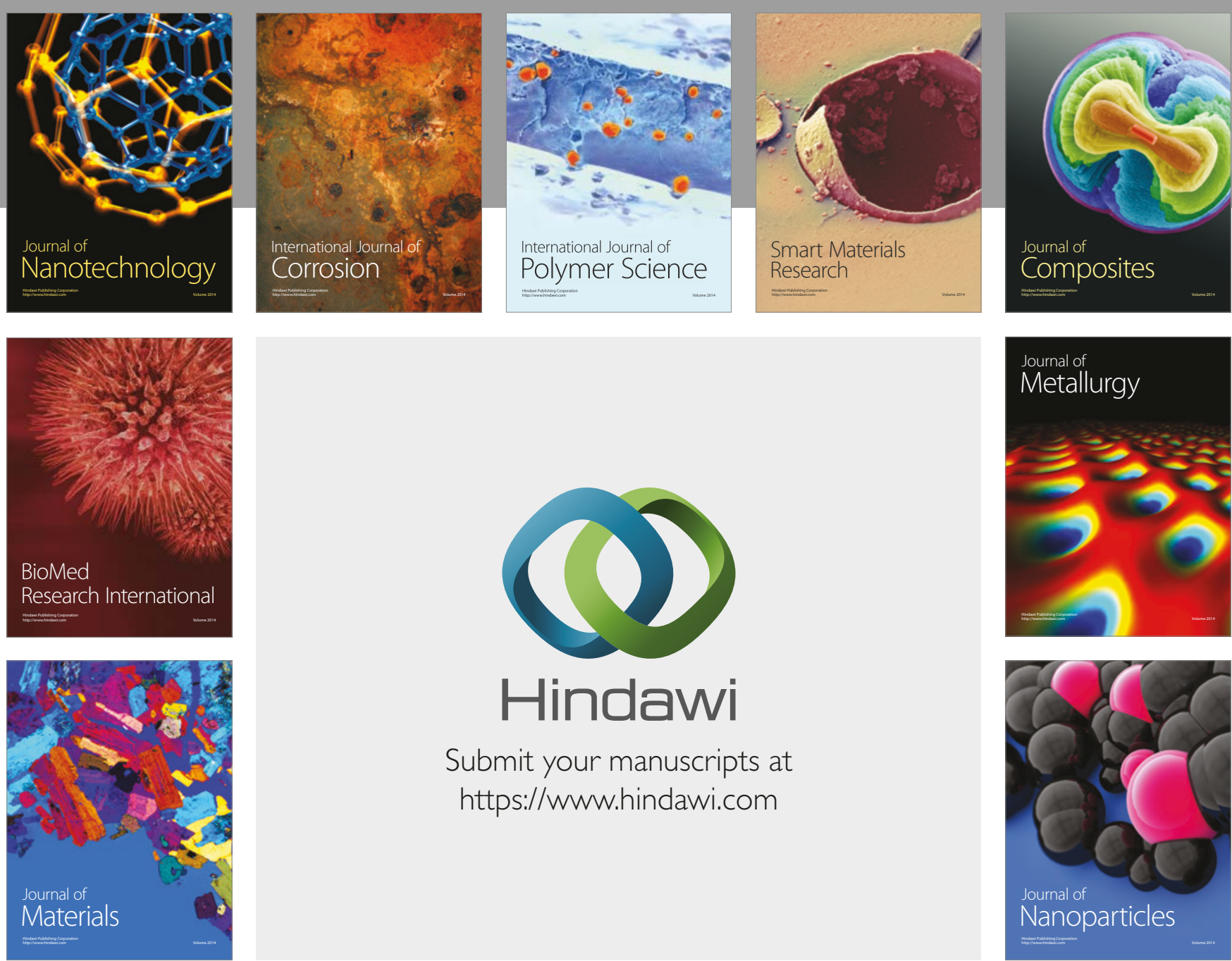

\section{Hindawi}

Submit your manuscripts at

https://www.hindawi.com
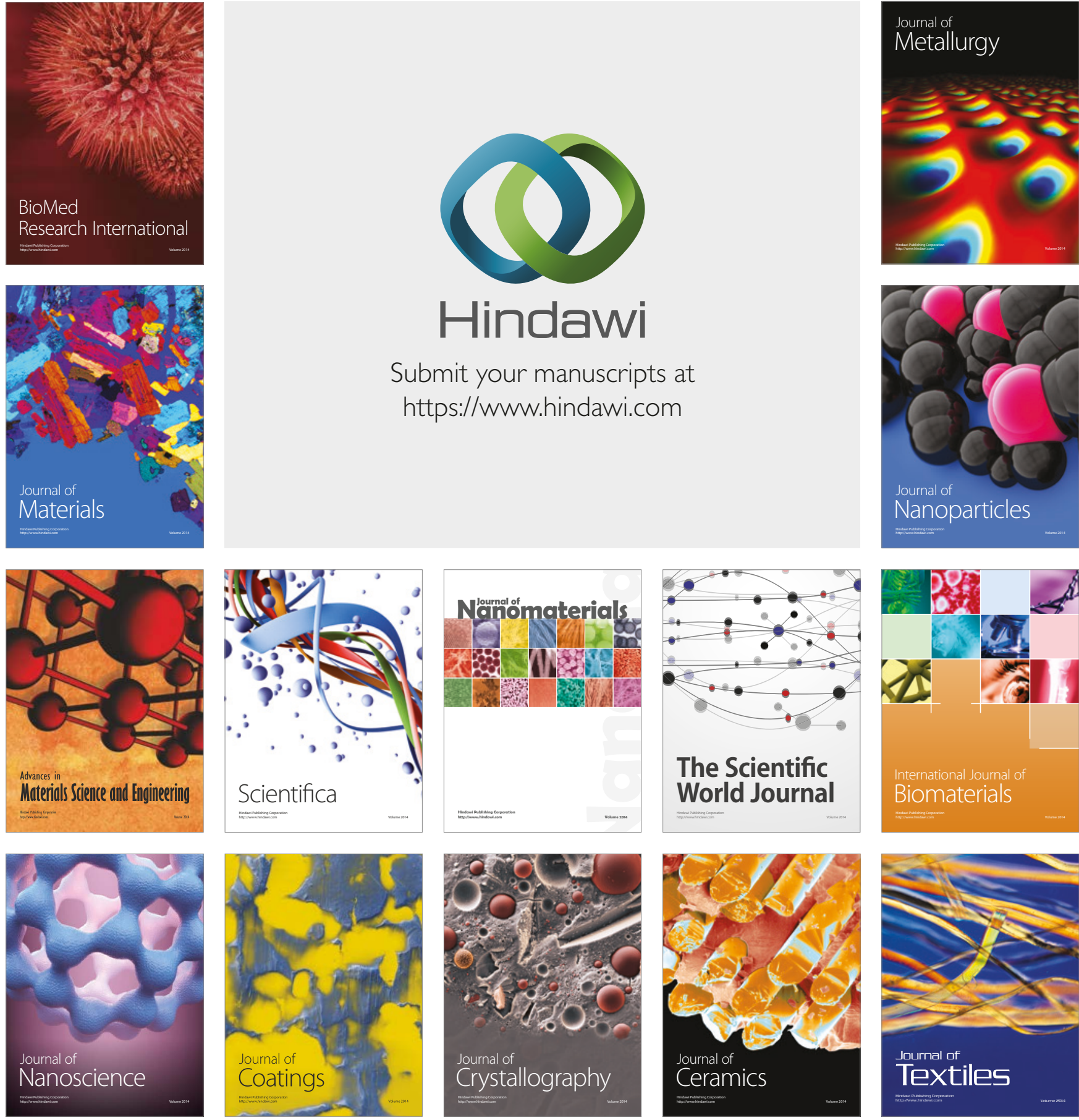

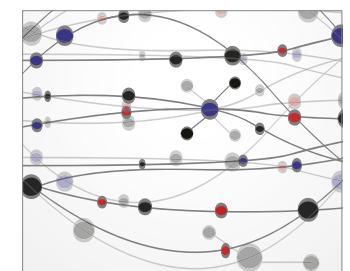

The Scientific World Journal
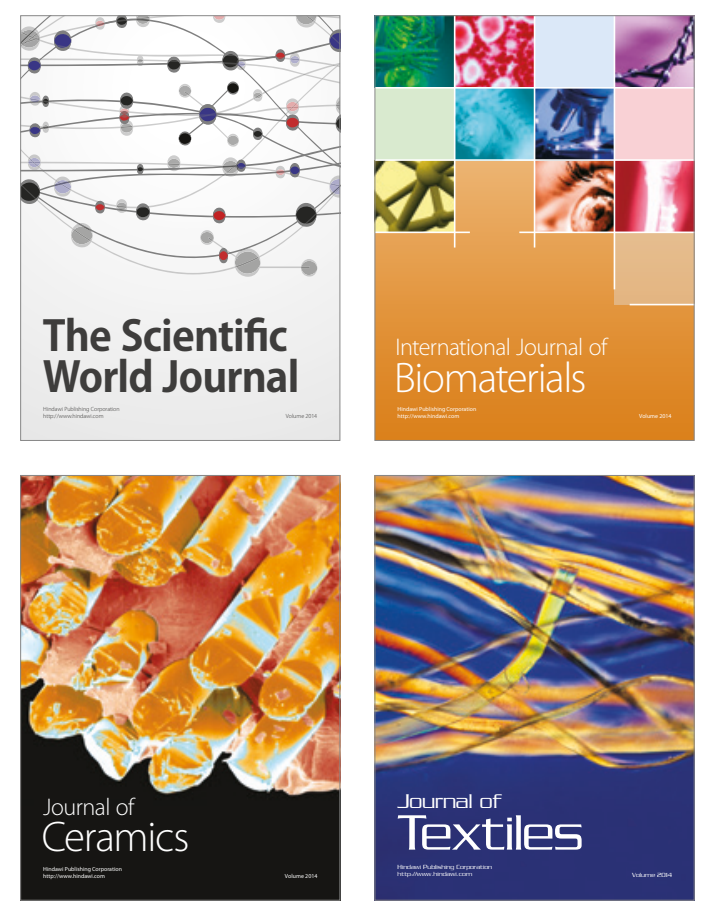